\title{
ОСОБЕННОСТИ МЕСТНОГО ИММУНИТЕТА У БЕРЕМЕННЫХ ПРИ НОВОЙ КОРОНАВИРУСНОЙ ИНФЕКЦИИ COVID-19
}

\section{FEATURES OF LOCAL IMMUNITY IN PREGNANT WOMEN WITH A NEW CORONAVIRUS INFECTION COVID-19 \\ I. Sakhautdinova \\ A. Khaibullina \\ I. Tayupova \\ I. Zasyadkin}

Summary. Coronavirus infection (COVID-19) is an acute viral disease caused by a new strain of RNA - genomic coronavirus SARS-CoV-2 with predominant upper respiratory tract damage. The infection, established by the UN in February 2020, remains relevant and spreading at lightning speed to this day. COVID-19 covered all continents in a matter of weeks and received the status of a particularly dangerous pandemic due to its contagiousness to humans. Coronavirus infection remains a polyethological disease with multisystem organ damage, which is based on hypoxia, vascular endothelial dysfunction, coagulopathy, hyperactivation of the immune response, as well as thrombosis. The particular interest of the COVID-19 pathogenesis in this work is focused on the local (local) immuno-inflammatory process, namely, the increase in pro- and anti-inflammatory mediators-cytokines in pregnant women infected with a new coronavirus infection. Due to the high risk of complications during pregnancy with COVID-19, the risk of maternal and perinatal mortality increases, making diagnosis and monitoring of pregnant women in the hospital a necessity. [6-8].

Keywords: interleukins, immunoglobulins, cytokines, coronavirus infection, pregnancy.

Б еременные женщины с коронавирусной инфекцией составляют не малую долю пациентов, поступающих в ковидные госпиталя с особой формой течения. Также данная группа пациентов требует тщательного стационарного наблюдения из-за риска осложнений беременности как со стороны ребенка, так и матери. Завершившиеся на сегодняшний день многочисленные исследования ученых Англии, Китая, США по форме течения клинической картины COVID-19 у беременных женщин, выявили закономерность особого течения и ряда отличий в симптомах коронавируса. Другим выявленным аспектом считается - высокая контагиозность (заражаемось) беременных, что подтвержда-
Сахаутдинова Индира Венеровна

Д.м.н., профессор, Башкирский государственный медицинский университет; Главный врач, чУЗ «КБ «РЖД-

Медицина» г. Уфра

Хайбуллина Альфия Рашитовна

К.м.н., дочент, Башкирский государственный медицинский университет alfiyahabullina@mail.ru

таюпова Ирина Маратовна

К.м.н., дочент, Башкирский государственный медицинский университет Засядкин Игорь Сергеевич

Ассистент, Башкирский государственный медицинский университет

Аннотация. Коронавирусная инфекция (COVID-19) - острое вирусное заболевание, вызываемое новым штаммом PHK-геномного коронавируса SARSCoV-2 с преимущественны поражение верхних дыхательных путей. Инфекция, установленная 00Н в феврале 2020 года, и по сей день остаётся актуальной и молниеносно распространяющейся. COVID-19 за считанные недели охватил все материки и получил статус особо опасной пандемии из-за своей контагиозности для человека. Коронавирусная инфекция остаётся полиэтиологическим заболеванием с мультисистемным поражением органов, в основе которого гипоксия, васкулярная эндотелиальная дисфункция, коагулопатия, гиперактивация иммунного ответа, а также тромбозы. Особый интерес патогенеза COVID-19 в данной работе сфокусирован на локальном (местном) иммуновоспалительном процессе, а именно на повышении про- и противоспалительных медиаторов-цитокинов у беременных женщин, инфицированных новой коронавирусной инфекцией. Из-за высокого риска осложнений при беременности с COVID-19 возрастает риск материнской и перинатальной смертности, делая диагностику и наблюдение за беременными в стационаре необходимостью[6-8].

Ключевые слова: интерлейкины, имуноглобулины, цитокины, коронавирусная инфекция, беременность.

ется научными статьями, опубликованными на сайте ВО3. Основными факторами риска в первую очередь считается возраст женщины и ее состояние здоровья. Особой группой риска беременные женщины наделяются и требуют особого контроля, если имеют какие-либо хронические заболевания в ремиссии или же с осложнениями, к примеру, сахарный диабет, артериальная гипертензия, бронхиальная астма, хроническая почечная недостаточность и другие $[2,15,17]$.

Коронавирусная инфекция у беременных протекает заметно в более тяжелой степени и лишь отрицательно может сказаться на их состояние. 
Иммуносупрессия и другие физиологические изменения во время беременности вызывают высокую восприимчивость к респираторным патогенам и повышают риск развития тяжелой пневмонии у беременных женщин, что может привести к госпитализации в отделения интенсивной терапии с последующей искусственной вентиляции легких (Alfaraj S.H., Al-Tawfiq J.A., 2019), что несёт риск развития бактериальных осложнений. Функционирование и состояние иммунной системы женщины во многом определяет направление развития патологических процессов в хроническом воспалении. На сегодняшний день первичными важнейшими звеньями в патогенезе хронического иммунологического воспаления является либо локальное нарушение системы крови, либо малые аномалии на системном уровне - вопрос остаётся открытым, является достаточно сложным, неоднозначным и до сих пор бурно дискутируемым как с иммунологических позиций, так и позиций общей патологии функционирования гомеостатических систем организма у беременных $[3,10,15]$.

В настоящее время особое внимание исследователей и целого ряда авторских групп сфокусировано на детальном выяснении роли цитокинов как «новая самостоятельная система саморегуляции» у беременных с COVID-19. Основываясь на анализе современной отечественной и зарубежной литературы только подтверждается вышеуказанное высказывание, ведь периферическая кровь в норме находится в состоянии «контролируемого» воспаления, и регулирует этот сложный баланс система воспалительных и противовоспалительных цитокинов в специфическом соотношении. Цитокины представляют собой группу эндогенных полипептидных медиаторов межклеточного взаимодействия, участвующую, главным образом, в формировании и регуляции защитно-приспособительных реакций организма на внедрение чужеродных для нашей иммунной системы патогенов различного генеза и нарушение целостности тканей, а также на регуляцию ряда нормальных физиологических функций [1]. Цитокины становятся пуском для комплекса интегративно-адаптивных реакций, вовлекают все разновидности клеток-эффекторов в элиминацию патогена из живого организма для полного его выздоровления. Если воспалительный процесс начинается с химических или же иных поломом, то реакция сопровождается бурным высвобождением провоспалительных цитокинов. Выявленная закономерность адаптивно-компенсаторного увеличения продукции цитокинов в ответ на патоген с целью купирования воспалительных процессов в организме определяет фазность данного процесса $[2,23,27,29]$. При генерализации инфекционного агента и сопутствующей воспалительной реакции в системе гемостаза, уровень провоспалительных цитокинов как маркер данного процесса - в большинстве случаев взаимосвязано возрастает $[3,28]$. Кроме того, особый интерес представляет данный аспект - при вирусной инфекции в крови активную роль играют биологические среды такие как индикатор интегральной оценки состояния, довольно мало изученные в свете цитокинового гомеостаза, требующие детального освящения вопроса $[4,5]$.

Система цитокинов, представляющая для нас особый интерес как важнейший первоначальный комплекс защитных факторов первой линии при внедрении патогенов различной этиологии, играющая роль формирования и регуляции общих защитных механизмов, в том числе токсических в отношении целостности тканей, позволяет с разных сторон охарактеризовать патогенетические механизмы, приводящие к началу и развитию каскада воспалительной реакции, и даёт возможность рассмотрения и определения лечения, направленного на данный механизм.

Клиническими и экспериментальными исследованиями доказано, что ведущей ролью в развитии иммунного ответа является активация системы цитокинов типа $\mathrm{Th}_{2}$, а продуцируемые $\mathrm{Th}_{2}$ интерлейкины как IL-4, IL-5, IL-9, IL-13, в свою очередь, усиливают образование иммуноглобулина E (IgE) [1]. Это первоначальное функциональное звено иммунитета ведёт к общему иммунному воспалению, деструкции тканей с одновременным вовлечением эффекторных клеток иммунной системы, развитием непредсказуемой реакции организма. Вместе с тем, несмотря, на обилие данных, касающихся вопросов воспаления тканей, в научном мире до сих пор нет единого мнения о направленности, взаимной детерминированности и глубине иммунных нарушений в период беременности. В то же время большинство исследователей характеризуют состояние иммунной системы у беременных как вторичный иммунодефицит. По определению В.С.Ширинского «Вторичный иммунодефицит представляет собой клинико-иммунологический синдром, основу которого составляют количественные и функциональные нарушения различных популяций и субпопуляций клеток моноцитарно-макро-фагальной системы, неспецифических факторов защиты, ассоциированных с развитием аутоиммунных, аллергических, инфекционных и опухолевых заболеваний» $[2,8,9]$. Из данного определения следует вывод о том, что состояние местных барьеров однозначно определяется уровнем пролиферации и дифференцировки иммунокомпетентных клеток в центральных органах иммуногенеза $[3,10,11]$. Не подлежит сомнению и тот факт, что индивидуальные особенности функционирования иммунной системы слизистых, во многом определяет направление развития патологических процессов в хроническом иммунологическом воспалении. При этом, чему отдана «пальма первенства» в патогенезе хронического иммунного воспаления - локальное нарушение на уровне 
Таблица 1. Содержание цитокинов в периферической крови у беременных с коронавирусной инфекцией (медиана, интерквартильный размах)

\begin{tabular}{|c|c|c|}
\hline Показатель (пг/мл) & $\begin{array}{l}\text { Контрольная группа (беременные без } \\
\text { коронавирусной инфекции) } \\
\text { n=23 }\end{array}$ & $\begin{array}{l}\text { Беременные с коронавирусной инфекцией } \\
\mathrm{n}=38\end{array}$ \\
\hline$I L-1 \beta$ & $\begin{array}{l}30,5 \\
{[8,8-36,7]}\end{array}$ & $\begin{array}{l}17,4^{* * *} \\
{[5,5-26,1]}\end{array}$ \\
\hline IL-6 & $\begin{array}{l}60,8 \\
{[24,3-75,5]} \\
\end{array}$ & $\begin{array}{l}28,6^{* * *} \\
{[21,1-40,5]} \\
\end{array}$ \\
\hline IL -8 & $\begin{array}{l}16,0 \\
{[12,0-21,0]}\end{array}$ & $\begin{array}{l}11,1^{* * *} \\
{[7,0-13,1]} \\
\end{array}$ \\
\hline IL -4 & $\begin{array}{l}8,5 \\
{[3,4-12,1]}\end{array}$ & $\begin{array}{l}42,2^{* * *} \\
{[35,3-57,9]}\end{array}$ \\
\hline IL -10 & $\begin{array}{l}5,3 \\
{[2,1-9,2]}\end{array}$ & $\begin{array}{l}1,3^{* * *} \\
{[0,9-2,1]}\end{array}$ \\
\hline TGF-1 $\beta$ & $\begin{array}{l}93,3 \\
{[36,2-129,2]} \\
\end{array}$ & \begin{tabular}{|l|}
$29,3^{* * *}$ \\
{$[21,2 ; 52,1]$} \\
\end{tabular} \\
\hline TNFa & $\begin{array}{l}24,4 \\
{[17,3-33,1]}\end{array}$ & \begin{tabular}{|l}
$102,2^{* * * *}$ \\
{$[27,3-156,3]$}
\end{tabular} \\
\hline
\end{tabular}

Примечание. Данные представлены в виде медиана (25-й, 75-й процентиль), статистическая значимость различий оценена критерием Манна-Уитни.

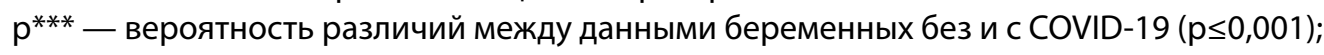

иммунной системы слизистых или же малые аномалии на системном уровне - неизвестно. Однако этот вопрос станет возможно основой для дальнейших исследований$[4,5,6]$.

\section{Цель исслеАования}

Целью исследования послужило изучение изменений иммунологического статуса и механизмов цитокиновой регуляции у беременных с коронавирусной инфекцией, анализ сдвигов иммуноглобулинов и цитокинов в крови для выяснения сопряжённости и направленности их нарушений, а также выявление возможных закономерностей в фазовом выделении цитокинов при инфекционном процессе в организме.

\section{Материал исслеАований}

Материалом исследований явилась периферическая кровь беременных, где изучалась концентрация иммуноглобулинов (lg) как $\lg A, \lg A, \lg M, \lg G, \lg$ и и цитокинов серологическим методом в условиях лаборатории.

\section{Результаты исслеАования}

Результатами исследования иммунологического статуса выявлено, что у всех беременных при коронавирусной инфекции отмечается повышенный местный гуморальный иммунодефицит. Иммунная система активно продуцирует медиаторы, способные стать защитой для организма.
По результатам исследования уровня цитокинов беременных женщин, инфицированных COVID-19, установлена закономерность дисбаланса цитокинов. Вследствие чего вывели критерии, которые могут стать основой прогностической шкалы оценки состояния беременной во время болезни. Выявление цитокинов показало срыва адаптационных процессов и нарастание инфекции в организме матери.

Для изучения цитокинов использовалось специальное современное оборудование, включающее в себя установку «Bio-Plex» («Bio-Rad Laboratories») с набором реагентов для анализа цитокинов (Bio-Plex Pro $^{\mathrm{TM}}$ Rat Cytokine $\mathrm{Th}_{1} / \mathrm{Th}_{2}$ Assay). Систему интерлейкинов IL-6 и IL-10 оценивали с использованием твёрдофазного иммуноферментного методов коммерческих диагностических наборов фирмы ЗАО «Вектор-Бест» (Новосибирск, Россия); IL-1 $\beta$, TNFa (фактор некроза опухоли а) - иммуноферментным методом с использованием реагентов «ProCon» («Протеиновый контур», Санкт-Петербург, Россия) на иммуноферментном анализаторе «Stat-Fax 2100», TGF-1 $\beta$ (трансформирующий фактор роста $\beta 1$ ) «Quintikin» (США); IL-4 и IL-8 - с помощью реагентов ООО «Цитокин» (Санкт-Петербург, Россия) по прилагаемым инструкциям, результаты выражали в мг/мл.

Программа STATISTICA v.6.0 (StatSoft Inc., США) стала основой для обработки полученных результатов. Средней ошибкой $(\mathrm{M} \pm \mathrm{m})$ представлены описательные статистики количественных, нормально распределенных данных. В зависимости от характера распределения пе- 
Таблица 2. Содержание иммуноглобулинов в периферической крови у беременных с коронавирусной инфекцией (медиана, интерквартильный размах)

\begin{tabular}{|c|c|c|}
\hline \multirow{3}{*}{ Показатель } & \multirow{3}{*}{$\begin{array}{l}\text { Контрольная группа (беременные без } \\
\text { коронавирусной инфекции) } \\
\mathrm{n}=23\end{array}$} & \multirow{3}{*}{$\begin{array}{l}\text { Беременные с коронавирусной инфекции } \\
\text { n=38 }\end{array}$} \\
\hline & & \\
\hline & & \\
\hline slgA, г/л & $\begin{array}{l}142,4 \\
{[74,2-188,3]}\end{array}$ & $\begin{array}{l}202,1^{* *} \\
{[177,7-211,1]}\end{array}$ \\
\hline $\lg \mathrm{A}, \mathrm{мг/л}$ & $\begin{array}{l}60,8 \\
{[45,1-90,6]} \\
\end{array}$ & $\begin{array}{l}44,5^{* *} \\
{[34,5-54,8]} \\
\end{array}$ \\
\hline $\operatorname{lgM}$, мг/л & $\begin{array}{l}3,3 \\
{[2,2-4,1]}\end{array}$ & $\begin{array}{l}1,5^{* * *} \\
{[0,8-2,8]}\end{array}$ \\
\hline $\operatorname{lgG}$, мг/л & $\begin{array}{l}11,0 \\
{[8,9-21,4]}\end{array}$ & $\begin{array}{l}7,5^{* * *} \\
{[4,8-9,2]}\end{array}$ \\
\hline $\lg \mathrm{E}, \mathrm{Mг} / л$ & $\begin{array}{l}1,7 \\
{[0,9-3,4]}\end{array}$ & $\begin{array}{l}1,1^{* * *} \\
{[0,4-1,2]} \\
\end{array}$ \\
\hline
\end{tabular}

Примечание. Данные представлены в виде медиана (25-й, 75-й процентиль), статистическая значимость различий оценена критерием Манна-Уитни.

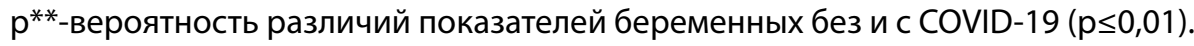

ременных была использованы медиана (Ме) и квартили [Q25; Q75]. Непараметрический U-критерий Манна-Уитни определял достоверность различий независимых выборок. Для качественных признаков использовались абсолютные значения и процентные доли. Сравнение групп с помощью критерия $X^{2}$. По r-критерию корреляционной зависимости Спирмена устанавливали силу и направленность связи признаков. F-критерий однофакторного дисперсионного анализа определял влияние независимых факторов на зависимую переменную. Критический уровень значимости $p$ при проверке взяли за 0,05.

Уровень провоспалительных (IL-1 $\beta$, IL-6, IL-8, TNFa) медиаторо-полипептидов вырос, тогда как противовоспалительные (IL-4, IL-10, TGF-1及) интерлейкины в периферической крови у беременных женщин при COVID-19 в исследовании заметно снизились (таблица1).

Максимальные сдвиги в нарастании цитокинов, статистически значимые для нашего исследования, обнаружены у беременных женщин с коронавирусной инфекцией. Так нарастание провоспалительных интерлейкинов обусловлено тяжестью заболевания.

Именно последние выполняют защитную роль, призывая в очаг инфекции нейтрофильные макрофаги, или же эффекторные клетки; также стимулируют их фагоцитарную и бактерицидную активность, и запускают антиген-специфический иммунный ответ, приводя к удалению агента. Но прогресс увеличения IL-1 1 и IL-8, так же хемоктантов на фоне снижения уровня IL-4 и IL-10 ведет к генерализации воспаления у пациенток. Установленная корреляционная связь концентрации IL-1 $\beta$, IL-6, IL-8 и TNFa от сроков беременности представлена для $I L-1 \beta$ как обратная средняя зависимость $(r=-0,22 ; p=0,08)$; для
$I L-6$ как прямая средняя зависимость $(r=0,43 ; p \leq 0,001)$; для $I L-8$ как прямая средняя зависимость $(r=0,45 ; p \leq$ $0,001)$ и для TNFa как сильная прямая корреляционная связь $(r=0,85 ; p \leq 0,001)$.

Содержание IL-10, ингибитора IL-1 $\beta$ и IL-8, снижается. Именно так помимо воспаления включается репарация. Из-за активации воспаления в системе крови к очагу поражения направляются нейтрофилы и эозинофилы, мононуклеарные фагоциты, активируются и синтезируют интерлейкины. Из-за дисфункции клеточно-опосредованных иммунных реакций растет концентрация IL-1 $\beta$, IL-6 и IL-8. Лимфоциты активируют $\mathrm{Th}_{1}$-иммунный ответ, но IL-10 слишком мало продуцируется, что ведет к обострению воспалительного процесса у беременных с коронавирусной инфекцией.

На основании выше изложенного, устанавливается статистическая закономерность дисбаланса соотношения про и противовоспалительных цитокинов у беременных пациенток ковидных госпиталей. Полученные информативные критерии станут основой для прогноза состояния пациентов в течении COVID-19. Это поможет определять необходимость купирования воспалительного ответа для предотвращения цитокинового шторма.

Результаты исследования концентрации иммуноглобулинов slgA, IgA, IgM, lgG, IgE у беременных с коронавирусной инфекцией (таблица 2), показывают о их неоднозначном изменении. Как видно, содержание slgA у беременных с коронавирусной инфекцией превышает исходное значение в 1,5 раза.

Данное изменение секреторного иммуноглобулина слизистых оболочек объясняется его эффекторной 
функцией, а именно агрегацией микробов и сорбцией их на поверхности эпителиальных клеток с угнетением роста микробов. Поэтому преобладание IgA и IgG у беременных с COVID-19 по сравнению с другими иммуноглобулинами (lgM, lgE) объясняется активным участием в первой фазе острого воспаления новой коронавирусной инфекции. Изучая дальше показатели крови можем наблюдать снижение показателей местного иммунитета, что клинически значимо у пациенток. Данный результат говорит о наличие иммунодефицита у беременных c COVID-19.

Таким образом, у беременных с коронавирусной инфекцией в целом отмечается повышенный местный гуморальный иммунодефицит.

Основываясь на корреляционном анализе беременных, выявлены умеренные связи внутри блока секреторных иммуноглобулинов периферической крови. В системе местного иммунитета выявлены умеренные корреляционные зависимости между: между $\operatorname{slg} \mathrm{A}$ и $\lg \mathrm{A}(r=0,62 ; p \leq 0,01) ; \operatorname{slg} \mathrm{A}$ и $\lg \mathrm{M}(r=0,28 ; p \leq 0,05)$; $\operatorname{slg} A$ и $\lg G(r=0,23 ; p \leq 0,05) ; \operatorname{sig} A$ и $\lg \mathrm{E}(r=0,26 ; p \leq 0,05)$; $\lg \mathrm{A}$ и $\lg \mathrm{M}(r=0,54 ; p \leq 0,01) ; \lg \mathrm{A}$ и $\lg \mathrm{g}(r=0,48 ; p \leq 0,05) ;$ между $\lg \mathrm{A}$ и $\lg \mathrm{E}(r=0,51 ; p \leq 0,01) ; \operatorname{lgM}$ и $\lg \mathrm{G}(r=0,45 ; p \leq 0,05) ; \lg \mathrm{M}$ и $\lg \mathrm{E}(r=0,49 ; p \leq 0,05) ; \lg \mathrm{E}$ и $\lg \mathrm{G}(r=0,46 ; p \leq 0,05)$. Значение коэффициентов парной корреляции варьировали от 0,28 до 0,62 , что характерно для умеренной силы корреляции.

Оценивая структуру корреляционной сети беременных с коронавирусной инфекцией, нами было определена сложность строения в сравнении с группой па- циенток беременных без коронавирусной инфекции. Корреляционные взаимодействие в этой группе беременных характеризуются усилением корреляции между блоками местного иммунитета.

Внутри блока параметров местного иммунитета связи умеренной силы отмечаются у slgA c IgA периферической крови $(r=0,62 ; p \leq 0,01) ;$ у slgA c $\operatorname{lgG}(r=0,39 ; p \leq 0,05)$; y slgA c lgM $(r=0,42 ; p \leq 0,05) ; \mathrm{y} \operatorname{slgA} c \lg \mathrm{E}(r=0,32 ; p \leq 0,05)$.

Число корреляционных зависимостей между показателями местного иммунитета было максимальным. Внутри блока параметров местного иммунитета связи умеренной силы отмечаются у $\operatorname{sg} \mathrm{A}$ с $\lg \mathrm{A}(r=0,68 ; p \leq 0,01)$; y slgA c IgG $(r=0,53 ; p \leq 0,01) ;$ y $\operatorname{slgA} c \lg M(r=0,42 ; p \leq 0,01)$; y $\operatorname{sig} \mathrm{A}$ c $\lg \mathrm{E}(r=0,50 ; p \leq 0,01) ;$ y $\lg \mathrm{A}$ и $\lg \mathrm{E}(r=0,56 ; p \leq 0,01)$; y $\lg M c \lg G(r=0,48 ; p \leq 0,01) ; y \lg M c \lg E(r=0,51 ; p \leq 0,01)$ и y $\lg \mathrm{E} c \lg \mathrm{g}(r=0,44 ; p \leq 0,01)$.

Таким образом, на основании полученных данных приходим к выводу о том, что математико-статистический анализ лабораторных данных показателей местного иммунитета подтвердил их значимую роль в поддержании гомеостаза у беременных с коронавирусной инфекцией преимущественно в начальную фазу острого воспаления. Из-за чего делаем вывод о повышенной активации иммунной системы беременных в этот период. Результаты корреляционного анализа послужили тому доказательством, так как выявлено усиление внутрисистемных взаимодействий защитных факторов на фоне фазового течения воспалительной инфекции в организме.

\section{ЛИТЕРАТУРА}

1. Ketlinskij S.A. Citokiny / S.A. Ketlinskij., A.S. Simbircev — SPb, 2008.

2. Biohimicheskie i patofiziologicheskie markjory himicheskogo vozdejstvija na organizm, ih informativnost'i diagnosticheskoe znachenie / R.I. Sabitova, E.D. Kravec, V.M. Samsonov, D.F. Shakirov i [dr.] // Klin. lab. diag.—2016.-T.61.-№ 1.—S.21-24.

3. Ocenka sostojanija nespecificheskoj zashhity organizma rabochih pri vozdejstvii toksicheskih faktorov proizvodstva himii i neftehimii /R.I. Sabitova, E.D. Kravec, Je.F. Galiullina, D.F. Shakirov, F.H. Kamilov, R.T., Buljakov, V.M. Samsonov, D.A. Enikeev // Kazan, med. zhurnal.— 2016.— № 5.— T.97.—S.784-792.

4. Leus, P.A. Smeshannaja sljuna (sostav, svojstva, funkcii) / P.A. Leus, O.S. Trockaja, S.S. Lobko, L.I. Palij.— Minsk, 2004.

5. Shirinskij V.S., Starostina I.M., Sennikova Ju.A., Malysheva 0.A. Problemy diagnostiki i klassifikacija vtorichnyh immunodeficitov. Allergologija i immunologija.2002. - T. 10. - № 1. - S. 62-71.

6. Sabitova R.I., Kravec E.D., Galiullina Je.F., Shakirov D.F., Kamilov F.H., Buljakov R.T., Samsonov V.M., Enikeev D.A. Ocenka sostojanija nespecificheskoj zashhity organizma rabochih pri vozdejstvii toksicheskih faktorov proizvodstva himii i neftehimii. Kazan, med. zhurnal.— 2016.— № 5. — T.97.-S.784-792.

7. Breslin N., Baptiste C., Gyamfi-Bannerman C., Miller R., Martinez R., Bernstein K. COVID-19 infection among asymptomatic and symptomatic pregnant women: Two weeks of confirmed presentations to an affiliated pair of New York City hospitals [published online ahead of print, 2020 Apr 9] Am J 0bstetGynecol MFM.2020:100118. doi: 10.1016/j.ajogmf.2020.100118.

( Сахаутдинова Индира Венеровна, Хайбуллина Альфия Рашитовна ( alfiyahabullina@mail.ru ),

Таюпова Ирина Маратовна, Засядкин Игорь Сергеевич.

Журнал «Современная наука: актуальные проблемы теории и практики» 